\title{
Isospora araponga sp. n. (Apicomplexa: Eimeriidae), a New Species of Isospora Schneider from a Bare-throated Bellbird, Procnias nudicollis (Vieillot, 1817) (Passeriformes: Cotingidae) from Brazil
}

\author{
Markéta Dolež alová, Jordi Torres*, Hugo Fernández**, David Modrý/***/+
}

\begin{abstract}
Department of Parasitology, University of Veterinary and Pharmaceutical Sciences, Palackého 1-3, Brno, 61242 Czech Republic *Laboratori de Parasitologia, Facultat de Farmàcia, Universitat de Barcelona, Barcelona, España **Parc Zoològic de Barcelona, Barcelona, España ***Institute of Parasitology, Academy of Sciences of the Czech Republic, Èeské Budì jovice, Czech Republic

Faecal samples from a couple of bare-throated bellbirds Procnias nudicollis imported from Brazil to Barcelona Zoo contained oocysts of Isospora araponga $n$. sp. Sporulated oocysts were subspherical to broadly ellipsoidal, $19.5(17-22) \times 15.5(14-16.5) \mu \mathrm{m}$, shape index (length:width ratio) 1.26 (1.13-1.38) with smooth and colourless bilayered wall, about $1 \mu \mathrm{m}$ thick, and with varying number (1-3) of polar granule, but without a micropyle or residuum. The sporocysts were ellipsoidal, slightly asymmetric, 12.5 (12-13) $\times 8.5$ (7.5-9) $\mu \mathrm{m}$ with barely visible Stieda body and indistinguishable substieda body. Sporozoites were elongated, possessing smooth surface and two distinct refractile bodies.
\end{abstract}

Key words: Isospora araponga n. sp. - Procnias nudicollis - Cotingidae - Brazil

Members of the Cotingidae are frugivorous or insectivorous passeriform birds inhabiting forests of subtropical and tropical America. So far, there were no species of coccidia reported from these hosts. The present study gives a description of a new species of Isospora from the bare throated bellbird Procnias nudicollis, species that is widely distributed from Brazil and Paraguay to Argentina.

\section{MATERIALS AND METHODS}

The faecal samples were collected during quarantine from a group of bare-throated bellbird, Procnias nudicollis (Vieillot, 1817), newly imported to Barcelona Zoo from Brazil. Exact locality of origin is unknown. Faecal material was kept at room temperature (at $19-21^{\circ} \mathrm{C}$ ) in $2.5 \%$ potassium dichromate to complete the sporulation. Then, oocysts were examined microscopically after flotation in modified Sheather's sugar solution $(\mathrm{s} . \mathrm{g} .=1.3)$. The oocysts were measured with an ocular micrometer and photographed with Olympus AX 70 microscope. All measurements are in micrometers, as means followed by range in parentheses.

\section{RESULTS}

Isospora araponga $\mathrm{n}$. sp.

Description - Oocysts are subspherical to broadly ellipsoidal, $19.5(17-22) \times 15.5(14-16.5)(\mathrm{n}=30)$; shape index (SI, length: width ratio) 1.26 (1.13-1.38). Micropyle and oocyst residuum are absent, varying number (1-3) of polar granules present, usually slightly elongated, $\sim 1$ in diameter. Oocyst wall is bilayered, $\sim 1.0$ thick, smooth and

${ }^{+}$Corresponding author. Fax: +4205.4156.2266. E-mail: modryd@vfu.cz

Received 23 June 2004

Accepted 3 November 2004 colourless. Sporocysts are ellipsoidal, slightly asymmetric, $12.5(12-13) \times 8.5(7.5-9), \mathrm{n}=30$; sporocyst $\mathrm{SI}=1.48$ (1.33-1.67). Typically, the sporocyst tightly fits the internal diameter of the oocyst. Stieda body is barely visible, appearing as a slightly refractile fine plug, $\sim 1$ wide; substieda body is indistinguishable. Sporocyst residuum is present, usually as a cluster $\sim 4$ in diameter, consisting of numerous fine granules. Sporozoites are elongated, possessing smooth surface and two distinct refractile bodies, Anterior refractile body is spherical, $\sim 2$ in diameter, the posterior one is bean shaped, $\sim 4 \times 3$.

Type host - Procnias nudicollis (Vieillot, 1817) (Aves: Passeriformes: Cotingidae), bare-throated bellbird.

Type locality - Material was isolated from faeces of captive birds imported to Barcelona from Brazil. Exact locality of origin is unknown.

Prevalence - Both $P$. nudicollis examined were infected. Site of infection - Unknown, oocysts recovered from faeces.

Sporulation - Exogenous, 5 days at $19-21^{\circ} \mathrm{C}$.

Type material - Photo-syntypes deposited under the collection nr R 73/2003 at Dept. of Parasitology, University of Veterinary and Pharmaceutical Sciences, Brno.

Etymology - The proposed specific epithet araponga, used herein as a noun in apposition, reflects the indigenous name of $P$. nudicollis.

\section{DISCUSSION}

I. araponga $\mathrm{n}$. sp. is the first coccidian species reported to date from any member of the Cotingidae. So far, there are around 50 species of Isopora described from passeriform birds resident to Latin America or migrating through this subcontitent (Pellérdy 1974, McQuistion \& Wilson 1988, 1989, McQuistion 1990, McQuistion \& Capparella 1992, 1994, 1997, McQuistion et al. 1996, 1997, 1999, http://biology.unm.edu/biology/coccidia/table.html). The species described herein as a new species differs 


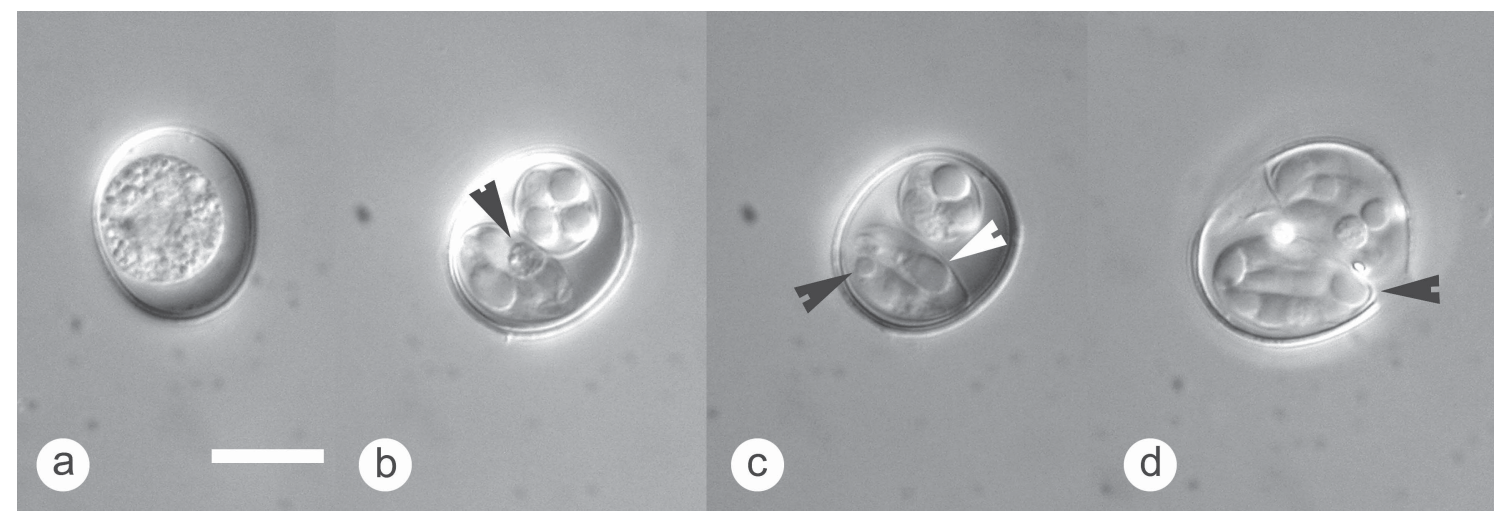

Fig. 1: Nomarski interference contrast (NIC) photographs of oocysts of Isospora araponga n.sp., all in the same scale, showing unsporulated (a) and sporulated oocysts (b-d), scale bar $=10 \mu \mathrm{m}$. Note compact sporocyst residuum (b, black arrowhead), anterior (c, black arrowhead), and posterior (c, white arrowhead) refractile bodies and fine Stieda body (d, black arrowhead).

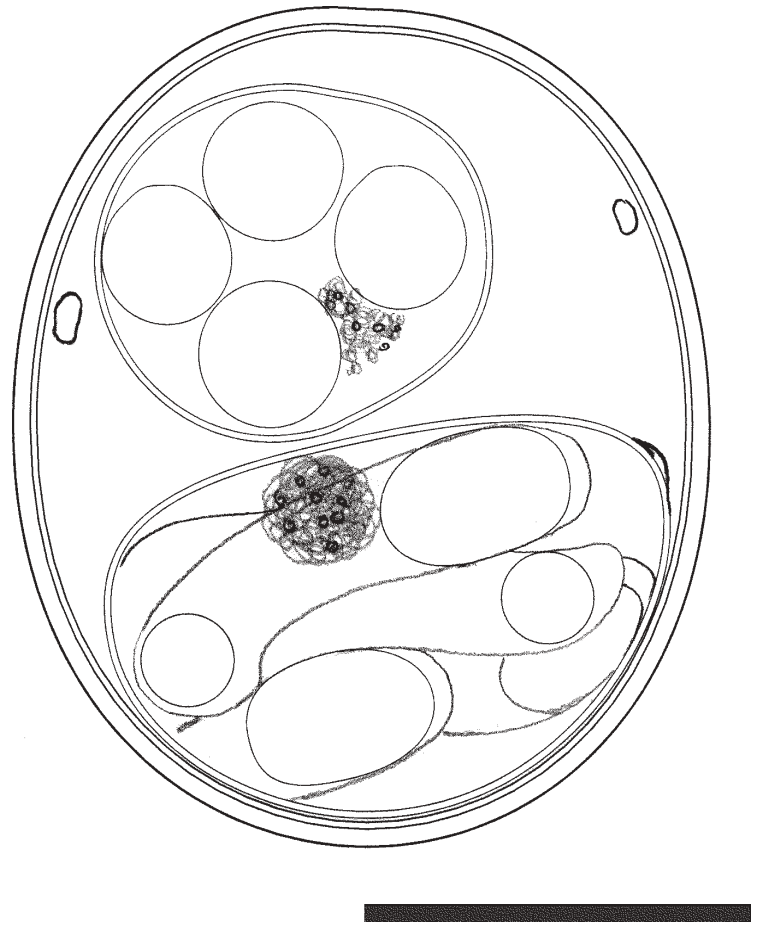

Fig. 2: composite line drawings of sporulated oocyst of Isospora araponga $\mathrm{n}$.sp., scale bar $=10 \mu \mathrm{m}$.

from all previously described isosporans from Latin America. The species most closely resembling I. araponga n. sp. are I. geospizae McQuistion and Wilson 1989 from Geospiza spp. from Galapagos and I. automoli Mc Quistion, Barber and Capparella 1999 from Automolus spp. from continental Ecuador (McQuistion \& Wilson 1989, McQuistion et al. 1999). However, I. araponga n.sp. differs from I. geospizae in oocyst morphology, being larger $(17-22 \times 14-16.5$ vs. $17 \times 13)$, and having much thicker oocyst wall. In contrast, oocysts of $I$. automoli are distinctly larger (17-24 × 18-28) than those of $I$. araponga n.sp. and possess only a single refractile body in each sporozoite. All above mentioned morphological traits, to- gether with host's systematics and distribution justify the description of $I$. araponga as a new species.

\section{ACKNOWLEDGEMENTS} tion.

To the staff of the Barcelona Zoo for its valuable contribu-

\section{REFERENCES}

McQuistion TE 1990. Isospora daphnensis n. sp. (Apicomplexa: Eimeriidae) from the medium ground finch (Geospiza fortis) from the Galapagos Islands. J Parasitol 76: 30-32.

McQuistion TE, Capparella A 1992. Two new coccidian parasites from the slate-colored grosbeak (Pitylus grossus) of South America. J Parasitol 78: 805-807.

McQuistion TE, Capparella A 1994. Two new species of Isospora (Apicomplexa: Eimeriidae) from ovenbirds (Passeriformes: Furnariidae) of South America. Trans Amer Microsc Soc 113: 90-95.

McQuistion TE, Capparella A 1997. Isospora ubique: a new coccidian parasite from the wedge-billed woodcreeper (Glyphorynchus spirurus) from South America. Acta Protozool 36: 75-78.

McQuistion TE, Wilson M 1988. Four new species of Isospora from the small tree finch (Camarhynchus parvulus) from the Galapagos Islands. J Protozool 35: 98-99.

McQuistion TE, Wilson M 1989. Isospora geospizae, a new coccidian parasite (Apicomplexa: Eimeriidae) from the small ground finch (Geospiza fulginosa) and the medium ground finch (Geospiza fortis) from the Galapagos Islands. Syst Parasitol 14: 141-144.

McQuistion TE, Barber CY, Capparella AP 1999. Isospora automoli, a new coccidian parasite (Apicomplexa: Eimeriidae) from the buff-throated foliage-gleaner Automolus ochrolaemus and the olive-backed foliage gleaner $A$. infuscatus from South America. Syst Parasitol 44: 71-73.

McQuistion TE, McAllister CT, Buice RE 1996. A new species of Isospora (Apicomplexa) from captive Pekin robins, Leiothrix lutea (Passeriformes: Sylviidae), from the Dallas Zoo. Acta Protozool 35: 73-75.

McQuistion TE, Walden KKO, Capparella AP 1997. Two new species of Isospora (Apicomplexa: Eimeriidae) from the ocellated woodcreeper, Xiphorhynchus ocellatus (Passeriformes: Dendrocolaptidae). Arch Protistenkd 147: 401404.

Pellérdy LP 1974. Coccidia and Coccidiosis, 2nd ed., Verlag Paul Parey, Berlin and Hamburg, 959 pp. 